\title{
Activation of Neutrophils within Pulmonary Microvessels of Rabbits Exposed to Cigarette Smoke
}

\author{
Maria E. Klut, Claire M. Doerschuk,' Stephanus F. Van Eeden, Alan R. Burns, \\ and James C. Hogg
}

University of British Columbia, Pulmonary Research Laboratory, St. Paul's Hospital, Vancouver, British Columbia, Canada

\begin{abstract}
Previous studies have shown that polymorphonuclear leukocytes (PMN) are delayed in the pulmonary capillaries by the presence of cigarette smoke. To determine if the PMN delayed by smoking are activated, we estimated the in vivo expression of CD11/CD18 and L-selectin on the surface of PMN in lungs and peripheral blood of rabbits because these molecules are known to be upregulated and downregulated, respectively, on the surface of activated PMN. New Zealand white rabbits $(3.5 \pm 0.1 \mathrm{~kg})$ were exposed to either air $(n=5)$ or cigarette smoke $(n=5)$, and we used an established protocol to measure pulmonary vascular blood flow, volume, and red blood cell (RBC) transit time in the left lung. The right lungs were then fixed in $0.025 \%$ glutaraldehyde and stored in liquid nitrogen. Ultrathin sections were immunolabeled with either the anti-CD18 monoclonal antibody 60.3 or the anti-L-selectin antibody Dreg-200, followed by a secondary antibody conjugated to $10 \mathrm{~nm}$ colloidal gold. The target antigens were quantified by counting the number of gold particles per micron $(\mathrm{G} / \mu \mathrm{m})$ of PMN surface membrane. The data show that smoke exposure had no effect on pulmonary blood flow, volume, or RBC transit time. However, it increased the expression of CD11/CD18 on intravascular PMN in the upper region of the lung (control, $7.4 \pm 1.3 \mathrm{G} / \mu \mathrm{m}$; smoke-exposed, $13.2 \pm 3.3 \mathrm{G} / \mu \mathrm{m} ; P<0.05)$ and decreased the expression of L-selectin on intravascular PMN in both the lower (control, $5.5 \pm 2.0 \mathrm{G} / \mu \mathrm{m}$; smoke-exposed, $2.6 \pm 1.5 \mathrm{G} / \mu \mathrm{m}$; $P=0.05$ ) and the upper (control, $6.8 \pm 1.4 \mathrm{G} / \mu \mathrm{m}$; smoke-exposed, $2.6 \pm 1.2 \mathrm{G} / \mu \mathrm{m} ; P<0.05$ ) regions. Smoke exposure did not significantly change the expression of the two adhesion molecules on circulating PMN. We conclude that the presence of cigarette smoke in the alveoli activates PMN in the microvessels of the lung.
\end{abstract}

The concept that emphysema is the result of a proteolytic lung destruction was introduced by the discovery that intratracheal instillation of papain caused an emphysema-like lung injury (1) and by the report of an association between $\alpha_{1}$-antitrypsin deficiency and emphysema (2). These observations led to the hypothesis that cigarette smoking caused emphysema by creating a proteolytic imbalance in the lung tissue $(3,4)$. This hypothesis has been tested by measuring

(Received in original form October 29, 1992 and in revised form February $5,1993)$

Address correspondence to: James C. Hogg, M.D., Ph.D., University of British Columbia, Pulmonary Research Laboratory, St. Paul's Hospital, Vancouver, BC V6Z 1Y6, Canada.

Abbreviations: $\alpha_{1}$-proteinase inhibitor, $\alpha_{1} \mathrm{PI}$; cardiac output, $\mathrm{CO}$; fluorescent-activated cell sorter, FACS; fluorescein isothiocyanate, FITC; gold particles per micron, $\mathrm{G} / \mu \mathrm{m}$; ${ }^{125}$ iodine-labeled macroaggregated albumin, I-MAA; phosphate-buffered saline, PBS; polymorphonuclear leukocyte(s), PMN; red blood cells, RBC; ${ }^{99 m}$ technitium-labeled RBC, Tc-RBC.

${ }^{1}$ Current address: Herman B. Wells Research Center, Department of Pediatrics, Riley Hospital for Children, Indiana University, Indianapolis, IN 46202-5225.

Am. J. Respir. Cell Mol. Biol. Vol. 9. pp. 82-89, 1993 the concentration of proteases and antiproteases in bronchoalveolar lavage fluid obtained from cigarette smokers and inconsistent results have been reported $(5,6)$.

More recently, active cigarette smoking has been shown to delay the transit of polymorphonuclear leukocytes (PMN) through the pulmonary capillary bed of both humans (7) and rabbits (8). These findings led us to postulate that the functional proteolytic imbalance responsible for centrilobular emphysema could be caused by PMN retained in the pulmonary microvessels. This imbalance might take place in the small intravascular pockets that form between the PMN and endothelial cells where proteolytic enzymes might remain active because they are protected from serum $\alpha_{1}$-proteinase inhibitor $\left(\alpha_{1} \mathrm{PI}\right)(9)$. The present study was designed to further examine this latter hypothesis by determining whether intravascular PMN that are delayed by cigarette smoke become activated. PMN activation is associated with an increased surface expression of the adhesion molecule CD11b/ CD18 and decreased expression (shedding) of a second adhesion molecule, L-selectin $(10,11)$. Therefore, the present study employed the immunogold technique and fluorescentactivated cell sorter (FACS) analysis to quantify the expression of these molecules on the surface of PMN in the lungs 
and circulating blood of rabbits that had been either exposed to cigarette smoke or sham exposed to air.

\section{Materials and Methods}

\section{Animal Preparation}

New Zealand white rabbits $(3.5 \pm 0.1 \mathrm{~kg}, n=10)$ were anesthetized with ketamine hydrochloride (80 to $100 \mathrm{mg} / \mathrm{kg}$ intramuscularly) and acepromazine maleate $(6$ to $8 \mathrm{mg} / \mathrm{kg}$ intramuscularly). Anesthesia was maintained by administering ketamine hydrochloride $(30 \mathrm{mg} / \mathrm{kg}$ intramuscularly). The ventral neck region was shaved, and the skin and subcutaneous tissue were anesthetized with subcutaneous injections of lidocaine. A midline incision allowed a polyethylene catheter to be inserted into the aorta through the left carotid artery. The airway was intubated through a tracheostomy. A butterfly catheter was placed in the marginal ear vein, and baseline blood samples were obtained for circulating blood cell counts and measurement of arterial blood gases and carboxyhemoglobin levels.

\section{Cigarette Smoke Exposure}

Cigarette smoke exposure was achieved using a technique that has been previously described in detail (8). Briefly, cigarette smoke was generated using unfiltered cigarettes and a smoking machine delivered smoke, at a rate of $4 \mathrm{puffs} / \mathrm{min}$ through a short tube, to a 250-ml cup placed over the tracheostomy opening. Rabbits exposed to the same procedure where the machine delivered room air rather than cigarette smoke served as controls. After 6 min of cigarette smoke $(n=5)$ or air $(n=5)$ exposure, the cardiac output was determined by injecting a $0.15 \mathrm{ml}(200,000$ to $400,000 \mathrm{cpm})$ bolus of ${ }^{99 \mathrm{~m}}$ technitium-labeled red blood cells (Tc-RBC) previously prepared from donor rabbit blood into the venous line and collecting blood samples, at 0.5 -s intervals, from the arterial line into preweighed tubes. Regional blood flow was measured by injecting ${ }^{125}$ iodine-labeled macroaggregated albumin (I-MAA) into the venous line, and pulmonary blood volume was measured by injecting additional Tc-RBC and allowing them to circulate for $5 \mathrm{~min}$. The smoke or air exposure lasted for a total of $12 \mathrm{~min}$ when a reference blood sample was collected for circulating blood cell counts and measurement of blood gases, carboxyhemoglobin, and radioisotope concentrations. The animal's heart was stopped by arterial injection of saturated $\mathrm{KCl}$. The chest was opened rapidly, the base of the heart was ligated, and the lungs were removed. The right lung was used for immunogold microscopic studies and the left lung for physiologic measurements.

\section{Physiologic Measurements}

The left lung was filled through the trachea with $6.0 \%$ glutaraldehyde in $0.1 \mathrm{M}$ phosphate-buffered saline (PBS, $\mathrm{pH}$ 7.3) and immersed in the same fixative for $1 \mathrm{~h}$. The lung was then cut into five slices perpendicular to the gravitational field, and these slices were further divided into 12 pieces that were placed in preweighed counting vials. These vials were then placed in a Beckman 8000 gamma well counter with the reference blood samples and blood samples from the indicator dilution run. The counts obtained were used to determine the levels of the individual isotopes using a computer pro- grammed to separate multiple isotopes and to correct for radiodecay and overlap.

\section{Calculations}

The cardiac output (CO) was calculated by the indicator dilution technique, using time versus concentration curves constructed from the blood fractions.

Regional blood flow and blood volume to each lung piece were calculated as fully described elsewhere (12):

$$
\begin{aligned}
\text { regional blood flow } & =\frac{\mathrm{CO} \times \mathrm{I}-\mathrm{MAA} \text { in lung piece }}{\text { total number I-MAA in lung }} \\
\text { blood volume } & =\frac{\mathrm{Tc}-\mathrm{RBC} \text { in lung piece }}{\mathrm{Tc}-\mathrm{RBC} / \mathrm{g} \text { blood }}
\end{aligned}
$$

The RBC transit time was then calculated as follows:

$$
\text { transit time }=\frac{\text { blood volume in each lung piece }}{\text { blood flow to the same lung piece }}
$$

The mean values of blood volume, blood flow, and RBC transit time for each slice in the left lung of five rabbits were calculated for each group. Because the right lung was fixed in a very low concentration $(0.025 \%)$ of glutaraldehyde which does not coagulate blood, it was not used in these physiologic calculations.

\section{Immunogold Microscopy}

The right lung was first inflated through its bronchus with ice-cold $0.025 \%$ glutaraldehyde in $0.1 \mathrm{M}$ PBS ( $\mathrm{pH} 7.3$ ), clamped, and immersion-fixed for $1 \mathrm{~h}$ in the same fixative at $4^{\circ} \mathrm{C}$. The fixed lung was then sectioned into five slices, perpendicular to the gravitational field: slice 1 represents the most gravity-dependent (lower) region and slice 5 the most independent (upper) region. Cubes $\left(\sim 2 \mathrm{~mm}^{3}\right)$ of lung tissue taken from slices 1 through 5 were additionally fixed for $1 \mathrm{~h}$ in cold $0.025 \%$ glutaraldehyde and then washed in $0.1 \mathrm{M}$ PBS. After cryoprotecting for $2 \mathrm{~h}$ in $2.3 \mathrm{M}$ sucrose, the samples were frozen in liquid nitrogen and stored until sectioned. Cryosections ( 80 to $100 \mathrm{~nm}$ thick), obtained on a RMC MT 6000-XL ultramicrotome equipped with a CR 2000 cryochamber, were immunolabeled for $30 \mathrm{~min}$, with the anti-CD18 monoclonal antibody 60.3 (kindly provided by Dr. J. M. Harlan, University of Washington) known to crossreact with $\mathrm{CD} 18$ on rabbit leukocytes (13), the anti-L-selectin monoclonal antibody Dreg-200 (kindly provided by Dr. E. C. Butcher), or the nonimmune mouse IgG (control). Sections were then labeled for $30 \mathrm{~min}$ with the $10 \mathrm{~nm}$ colloidal gold-conjugated goat anti-mouse secondary antibody (Sigma) (14). After embedding and contrasting with methylcellulose and uranyl acetate (15), cryosections were observed on a Philips TEM 400.

\section{Morphometric Studies}

Electron micrographs, 40 to $80 /$ region/animal group at 27,500 magnification, from the lung slices of each animal were used to measure the length ( $5 \mu \mathrm{m}$ minimum) of the PMN plasma membrane on a tablet digitizer and to count the number of gold particles per micron $(\mathrm{G} / \mu \mathrm{m})$ of PMN surface membrane. 
TABLE 1

Carboxyhemoglobin and arterial blood gases concentration: circulating blood cell and platelet counts*

\begin{tabular}{|c|c|c|c|c|}
\hline & \multicolumn{2}{|c|}{$\begin{array}{c}\text { Smoke } \\
(n=5)\end{array}$} & \multicolumn{2}{|c|}{$\begin{array}{l}\text { Control } \\
(n=5)\end{array}$} \\
\hline & 0 Time & $12 \mathrm{~min}$ & 0 Time & $12 \mathrm{~min}$ \\
\hline Carboxyhemoglobin (\%) & $6.4 \pm 0.8$ & $10.3 \pm 1.1$ & $7.6 \pm 1.0$ & $7.3 \pm 1.0$ \\
\hline $\mathrm{PaO}_{2}(\mathrm{~mm} / \mathrm{Hg})$ & $107 \pm 8$ & $100 \pm 5$ & $117 \pm 6$ & $114 \pm 3$ \\
\hline $\mathrm{PaCO}_{2}(\mathrm{~mm} / \mathrm{Hg})$ & $41.0 \pm 2.2$ & $43.1 \pm 1.5$ & $40.6 \pm 1.4$ & $42.4 \pm 2.0$ \\
\hline pH & $7.4 \pm 0.1$ & $7.3 \pm 0.01$ & $7.4 \pm 0.02$ & $7.4 \pm 0.02$ \\
\hline Neutrophils $\left(\times 10^{6} / \mathrm{ml}\right)$ & $3.4 \pm 0.6$ & $3.1 \pm 0.5$ & $3.4 \pm 0.4$ & $3.4 \pm 0.4$ \\
\hline Lymphocytes $\left(\times 10^{6} / \mathrm{ml}\right)$ & $4.5 \pm 0.7$ & $4.2 \pm 0.5$ & $3.5 \pm 0.2$ & $3.1 \pm 0.2$ \\
\hline Platelets $\left(\times 10^{6} / \mathrm{ml}\right)$ & $278 \pm 29$ & $293 \pm 26$ & $299 \pm 21$ & $299 \pm 9$ \\
\hline
\end{tabular}

$*$ Values are expressed as mean $\pm \mathrm{SE}$.

Intra- and inter-observer differences were determined by randomly selecting 20 electron microscopy negatives from a total of 507. The prints from these negatives were recounted by the observer (M.E.K.), who made all of the primary observations, and by a second observer (A.R.B.), who is experienced with this technique. Neither observer was aware of whether the negatives were from the control or smoke-exposed animals.

\section{Statistical Analysis}

A mean value and SD were calculated for each lung region in each of the five rabbits. This mean value was then used to calculate the regional mean value and SD for the group. Differences between groups were determined by an analysis of variance (16) and $P \leqslant 0.05$ was considered significant. To estimate the between group variability of the gold labeling density on the PMN cell surface, we calculated the percentage of PMN that expressed increasing amounts of $\mathrm{G} / \mu \mathrm{m}$.

\section{Immunofluorescence Flow Cytometry}

The expression of CD11/CD18 and L-selectin on circulating PMN was determined on a separate group of smoke-exposed $(n=5)$ and sham-exposed $(n=5)$ rabbits prepared as described above. Mixed venous blood was collected into EDTA before and after exposure, and these specimens were prepared for indirect immunofluorescence using a whole blood lysis method (Coulter Immunology, Hialeah, FL). Blood was incubated with the primary antibody (60.3 or Dreg-200) for $10 \mathrm{~min}$, at room temperature, followed by fluorescein isothiocyanate (FITC)-conjugated goat anti-mouse (Sigma) with further incubation for 10 min in the dark. RBC were lysed and the leukocytes were fixed with $1 \%$ paraformalde-

TABLE 2

Cardiac output, left lung blood volume, blood flow, and RBC transit time

\begin{tabular}{lcc}
\hline & $\begin{array}{c}\text { Smoke } \\
(n=5)\end{array}$ & $\begin{array}{c}\text { Control } \\
(n=5)\end{array}$ \\
\hline Cardiac output (ml/min) & $558 \pm 18$ & $491 \pm 19$ \\
Blood volume (ml) & $4.6 \pm 0.7$ & $4.0 \pm 0.2$ \\
Blood flow (ml/min) & $271 \pm 12$ & $269 \pm 10$ \\
RBC transit time (s), mean & $1.1 \pm 0.2$ & $1.1 \pm 0.1$ \\
RBC transit time (s), lower & $0.84 \pm 0.14$ & $0.85 \pm 0.24$ \\
RBC transit time (s), upper & $1.42 \pm 0.78$ & $1.50 \pm 0.67$ \\
\hline
\end{tabular}

hyde. Nonimmune FITC-conjugated mouse $\mathrm{IgG}_{1}$ (Becton Dickinson) was used as control. Analysis was performed on a flow cytometer (Epics ${ }^{\circledR}$-Profile II; Coulter Electronics, Hileah, FL), and results were expressed as the mean fluorescence intensity of 3,000 PMN. Analysis gates for PMN were defined on dot plots of forward light scatter versus side scatter.

\section{Results}

\section{Carboxyhemoglobin Levels and Physiologic Data}

Table 1 shows that the carboxyhemoglobin concentration increased ( $4 \%)$ in rabbits exposed to cigarette smoke for 12 min but showed no change in the control group. Neither group showed any change in either $\mathrm{PaO}_{2}, \mathrm{PaCO}_{2}, \mathrm{pH}$, or in the neutrophil, lymphocyte, and platelet counts (Table 1). Cardiac output, left lung blood volume, blood flow, and RBC

TABLE 3

CD11/CD18 expression on the surface of PMN in five regions of two rabbits*

\begin{tabular}{lccccc}
\hline & \multicolumn{5}{c}{ Lung Region } \\
\cline { 2 - 6 } Exposure & 1 (lower) & 2 & 3 & 4 & 5 (upper) \\
\hline Control & $8.6 \pm 3.2$ & $6.9 \pm 4.4$ & $3.6 \pm 3.4$ & $4.8 \pm 1.0$ & $5.4 \pm 3.4$ \\
Smoke & $9.2 \pm 2.6$ & $7.3 \pm 2.3$ & $5.9 \pm 5.3$ & $7.8 \pm 4.1$ & $15.6 \pm 6.4$ \\
\hline
\end{tabular}

* Results of preliminary experiments that led us to focus on upper and lower regions of the larger group of animals shown in Table 4. Values are expressed as mean $\pm \mathrm{SD}$ of $\mathrm{G} / \mu \mathrm{m}$ of plasma membrane.

TABLE 4

$C D 11 / C D 18$ expression on the surface of PMN in lung microvessels*

\begin{tabular}{|c|c|c|c|c|}
\hline \multirow[b]{2}{*}{ Rabbit } & \multicolumn{2}{|c|}{ Lower Region } & \multicolumn{2}{|c|}{ Upper Region } \\
\hline & Control & Smoke & Control & Smoke \\
\hline 1 & $8.6 \pm 3.2$ & $9.2 \pm 2.6$ & $5.4 \pm 3.4$ & $15.6 \pm 6.4$ \\
\hline 2 & $4.4 \pm 2.1$ & $9.2 \pm 4.2$ & $8.1 \pm 3.4$ & $16.1 \pm 5.7$ \\
\hline 3 & $4.3 \pm 3.5$ & $6.1 \pm 2.1$ & $9.1 \pm 3.4$ & $15.2 \pm 6.1$ \\
\hline 4 & $8.0 \pm 4.6$ & $7.0 \pm 2.9$ & $7.6 \pm 2.7$ & $9.9 \pm 2.8$ \\
\hline 5 & $8.4 \pm 4.7$ & $6.1 \pm 3.7$ & $6.9 \pm 2.4$ & $9.3 \pm 5.6$ \\
\hline Mean & $6.7 \pm 2.2$ & $7.6 \pm 1.4$ & $7.4 \pm 1.3$ & $13.2 \pm 3.3^{\dagger}$ \\
\hline
\end{tabular}



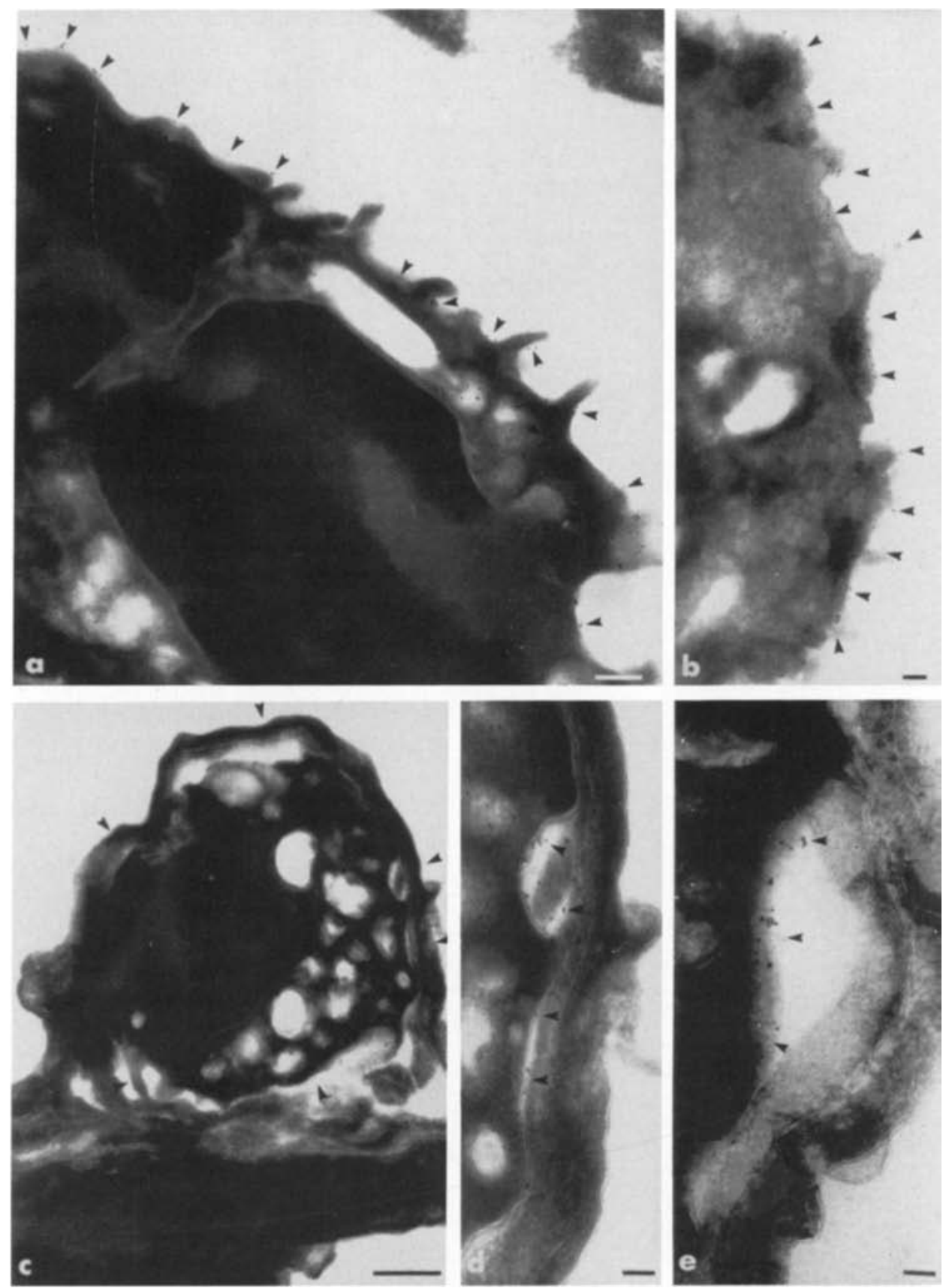

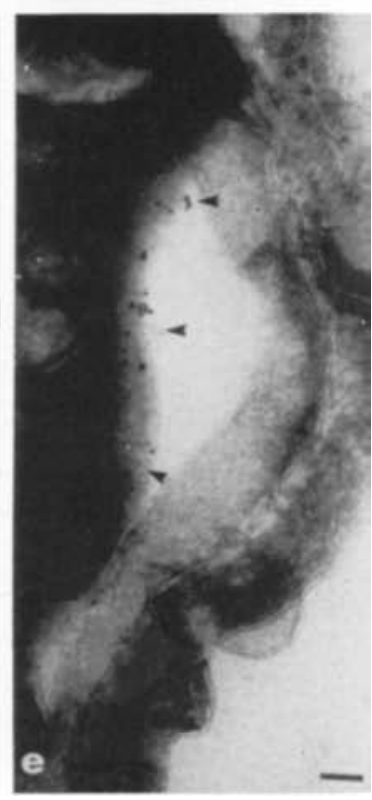

Figure 1. Expression (arrowheads) of $\mathrm{CD} 11 / \mathrm{CD} 18$ on the surface of PMN, in smoke-exposed rabbits, in the: (a) lower region of the lung (bar $=0.2 \mu \mathrm{m}$ ). (b) Upper lung region (bar $=0.1$ $\mu \mathrm{m})$. (c through e) Pocket areas (bars $=1 \mu \mathrm{m}$ in panel $\mathrm{c}$ and 0.1 $\mu \mathrm{m}$ in panels $\mathrm{d}$ and $\mathrm{e}$ ).

TABLE 5

Variability in $C D 11 / C D 18$ expression on rabbit $P M N^{*}$

\begin{tabular}{|c|c|c|c|c|c|c|}
\hline \multirow[b]{2}{*}{ Exposure } & \multirow[b]{2}{*}{ Region } & \multicolumn{5}{|c|}{$\mathrm{G} / \mu \mathrm{m}$} \\
\hline & & $<4$ & $\geqslant 4<8$ & $\geqslant 8<12$ & $\geqslant 12<16$ & $\geqslant 16$ \\
\hline Control & $\begin{array}{l}\text { Lower } \\
\text { Upper }\end{array}$ & $\begin{array}{l}28.5 \pm 15.1 \\
11.7 \pm 15.1\end{array}$ & $\begin{array}{l}35.7 \pm 17.7 \\
53.2 \pm 7.9\end{array}$ & $\begin{array}{l}19.7 \pm 18.7 \\
23.4 \pm 14.1\end{array}$ & $\begin{array}{l}14.2 \pm 13.3 \\
11.7 \pm 9.1\end{array}$ & $\begin{array}{l}0.0 \pm 0.0 \\
0.0 \pm 0.0\end{array}$ \\
\hline Smoke & $\begin{array}{l}\text { Lower } \\
\text { Upper }\end{array}$ & $\begin{array}{l}8.7 \pm 7.2 \\
1.0 \pm 2.2\end{array}$ & $\begin{array}{l}55.4 \pm 16.5 \\
17.4 \pm 15.7\end{array}$ & $\begin{array}{l}25.7 \pm 19.9 \\
23.7 \pm 21.2\end{array}$ & $\begin{array}{c}7.5 \pm 8.1 \\
20.9 \pm 14.9\end{array}$ & $\begin{array}{c}2.8 \pm 4.1 \\
29.6 \pm 23.9\end{array}$ \\
\hline
\end{tabular}

* Values are mean $\% \pm$ SD of PMN for five rabbits. 
TABLE 6

L-selectin expression on the surface of PMN in lung microvessels*

\begin{tabular}{lcccc} 
& \multicolumn{2}{c}{ Lower Region } & \multicolumn{2}{c}{ Upper Region } \\
\cline { 2 - 3 } \cline { 5 - 5 } Rabbit & Control & Smoke & Control & Smoke \\
\hline 1 & $4.1 \pm 3.4$ & $1.4 \pm 1.2$ & $4.9 \pm 2.7$ & $1.9 \pm 1.6$ \\
2 & $6.9 \pm 2.9$ & $2.5 \pm 1.5$ & $5.7 \pm 3.5$ & $2.7 \pm 3.0$ \\
3 & $2.8 \pm 1.3$ & $1.9 \pm 1.8$ & $7.5 \pm 3.9$ & $3.1 \pm 2.6$ \\
4 & $7.5 \pm 3.2$ & $5.2 \pm 2.3$ & $8.0 \pm 5.4$ & $1.1 \pm 0.7$ \\
5 & $6.2 \pm 5.7$ & $1.8 \pm 0.6$ & $7.9 \pm 3.4$ & $4.2 \pm 3.1$ \\
Mean & $5.5 \pm 2.0$ & $2.6 \pm 1.5$ & $6.8 \pm 1.4$ & $2.6 \pm 1.2 \ddagger$ \\
\hline
\end{tabular}

* Values are mean \pm SD of G/ $\mu \mathrm{m}$ of PMN surface membrane.

$+\boldsymbol{P}=0.05$, smoke versus control.

$\ddagger P<0.05$, smoke versus control.

transit time were not different (Table 2). The regional blood volume was similar in all lung slices in both groups, and blood flow showed the expected decrease in the gravitydependent regions (slices 4 and 5) in both groups (data not shown). The RBC transit time through the left lung was similar (control versus smoke) but tended to increase in the upper regions of the lung of both groups (Table 2).

\section{Expression of CD11/CD18 on PMN Cell Surface}

Table 3 shows data from the initial immunogold studies performed on one control and one smoke-exposed rabbit lung. CD11/CD18 expression on the PMN surface varied from 4 to $9 \mathrm{G} / \mu \mathrm{m}$ in the control lung with no significant difference between lung regions. In the smoke-exposed animal on the other hand, PMN within the upper region increased their $\mathrm{CD} 11 / \mathrm{CD} 18$ expression to $15.6 \mathrm{G} / \mu \mathrm{m}(P<0.05)$. Based on these results, we concentrated on the upper and lower regions of the lung of the remaining animals.

Table 4 shows that smoke exposure caused CD11/CD18 expression on the surface of PMN, in the upper region of the lung, to increase from $7.4 \pm 1.3 \mathrm{G} / \mu \mathrm{m}$ to $13.2 \pm 3.3 \mathrm{G} / \mu \mathrm{m}$ $(P<0.05)$. In contrast, $\mathrm{CD} 11 / \mathrm{CD} 18$ expression on the PMN in the lower lung region of the smoked-exposed animals was not statistically different from that in the controls $(P>0.05)$. Nonspecific labeling (nonimmune mouse $\mathrm{IgG}$ ) was $0.14 \pm$ $0.16 / \mu \mathrm{m}$. Morphologic observations showed that PMN appeared round with an undulated to elongated surface (polarized) with distinct ruffles. The CD11/CD18 immunogold complexes occur as single or cluster units (Figure la). They show enhanced surface expression in the PMN of the upper region (Figure $\mathrm{lb}$ versus la), including pocket areas formed between the PMN plasma membrane and the endothelium (Figures 1c to 1e).
Figure 2. Expression (arrowheads) of L-selectin on the surface of PMN in the lower region of: (a, b) Control (bar $=0.2 \mu \mathrm{m})$. Note L-selectin expression on microvillar projections. (c) Smokeexposed rabbit. Note low labeling density (bar $=0.5 \mu \mathrm{m}$ ).
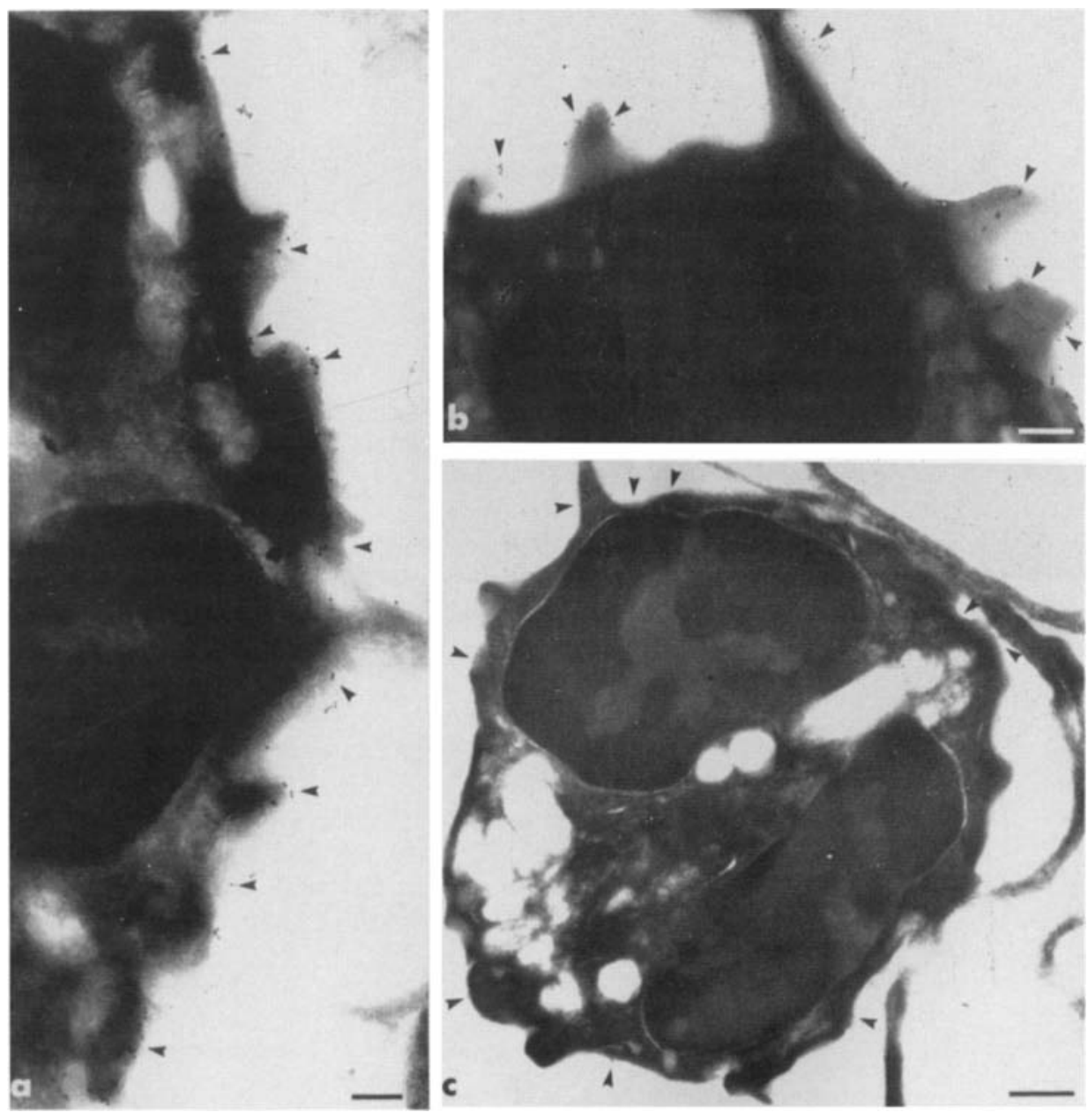
TABLE 7

Variability in L-selectin expression on rabbit PMN*

\begin{tabular}{|c|c|c|c|c|c|}
\hline \multirow[b]{2}{*}{ Exposure } & \multirow[b]{2}{*}{ Region } & \multicolumn{4}{|c|}{$\mathrm{G} / \mu \mathrm{m}$} \\
\hline & & $\leqslant 2$ & $>2 \leqslant 4$ & $>4 \leqslant 6$ & $>6$ \\
\hline \multirow[t]{2}{*}{ Control } & Lower & $17.0 \pm 13.2$ & $29.6 \pm 17.3$ & $11.8 \pm 7.3$ & $41.6 \pm 28.8$ \\
\hline & Upper & $8.5 \pm 11.6$ & $17.3 \pm 7.3$ & $23.4 \pm 8.4$ & $50.9 \pm 11.9$ \\
\hline \multirow[t]{2}{*}{ Smoke } & Lower & $46.5 \pm 30.3$ & $37.7 \pm 18.4$ & $10.1 \pm 12.1$ & $5.7 \pm 12.8$ \\
\hline & Upper & $59.4 \pm 25.3$ & $19.0 \pm 15.4$ & $12.1 \pm 10.9$ & $9.5 \pm 9.1$ \\
\hline
\end{tabular}

* Values are mean \% \pm SD of PMN for five rabbits.

Table 5 shows that the majority $(>60 \%$ ) of PMN in both the lower and the upper lung regions of control animals, as well as in the lower lung region of smoke-exposed animals, had less than $8 \mathrm{G} / \mu \mathrm{m}$ and none or few (3\%) contained 16 or more $\mathrm{G} / \mu \mathrm{m}$. In contrast, in the upper lung region of the smoke-exposed animals $30 \%$ of the PMN had 16 or more $\mathrm{G} / \mu \mathrm{m}$ and only a few $(18 \%)$ contained less than $8 \mathrm{G} / \mu \mathrm{m}$.

\section{Expression of L-selectin on PMN Cell Surface}

Parallel immunocytochemical studies performed in the same lung tissue, using the mAb Dreg-200, showed that in control samples L-selectin expression on the surface of PMN in both upper and lower lung regions was 6 to $7 \mathrm{G} / \mu \mathrm{m}$ (Table 6 ). However, following smoke exposure this expression decreased from $5.5 \pm 2.0 \mathrm{G} / \mu \mathrm{m}$ to $2.6 \pm 1.5 \mathrm{G} / \mu \mathrm{m}(P=0.05)$ in the lower region (see also labeling in Figures $2 \mathrm{a}$ and $2 \mathrm{~b}$, versus $2 \mathrm{c}$ ) and from $6.8 \pm 1.4 \mathrm{G} / \mu \mathrm{m}$ to $2.6 \pm 1.2 \mathrm{G} / \mu \mathrm{m}$ in the upper region $(P<0.05)$.

Table 7 shows that in both the lower and upper lung regions of control rabbits the majority of PMN had more than $6 \mathrm{G} / \mu \mathrm{m}$. Following smoke exposure, most of the PMN in both lower and upper regions showed 2 or less $\mathrm{G} / \mu \mathrm{m}$ and less than $10 \%$ showed a labeling density greater than 6 $\mathrm{G} / \mu \mathrm{m}$.

\section{Intra- and Inter-observer Differences}

The data concerning the reproducibility of the observations showed an excellent reproducibility when the same observer repeated the measurements on two occasions. Observer 1: slope $=0.960$, intercept $=2.393$, correlation $=0.998$ Observer 2: slope $=0.950$, intercept $=9.837$, correlation $=$ 0.984 . Comparison of these two observers showed excellent correlation although observer 1 consistently obtained slightly higher values than observer 2 (slope, 1.796; intercept = -6.977 ; correlation, 0.909).

TABLE 8

Expression of L-selectin and CD11/CD18 (mean fluorescence intensity), as measured with $F A C S$ analysis, on circulating $P M N^{*}$

\begin{tabular}{lcccrr}
\hline & \multicolumn{2}{c}{ Control } & \multicolumn{2}{c}{ Smoke } \\
\cline { 2 - 3 } \cline { 5 - 6 } \cline { 5 - 6 } & Baseline & $12 \mathrm{~min}$ & & Baseline & $12 \mathrm{~min}^{\dagger}$ \\
\hline L-selectin & $9.26 \pm 1.2$ & $9.42 \pm 0.8$ & $9.24 \pm 0.8$ & $10.5 \pm 1.3$ \\
CD11/CD18 & $6.62 \pm 2.0$ & $7.34 \pm 1.9$ & $6.9 \pm 1.3$ & $6.5 \pm 1.7$ \\
\hline
\end{tabular}

* Values are mean $\pm S D$ of five rabbits.

† Change not significant from baseline.

\section{Expression of CD11/CD18 and L-selectin} on Circulating PMN

The expression of $\mathrm{CD} 11 / \mathrm{CD} 18$ and $\mathrm{L}$-selectin on circulating PMN did not change significantly from baseline in either the control or smoke-exposed rabbits (Table 8). However, in two experiments a population of PMN with low expression of $\mathrm{L}$-selectin was seen in two rabbits after 12 min of smoking, suggesting intravascular shedding of L-selectin. One of these FACS analysis is shown in Figure 3.

\section{Discussion}

Previous studies have established that airway instilled with proteolytic enzymes produces massive lung destruction, whereas intravenous injection of the same enzymes has little or no effect (1). These observations suggest that the proteolytic process responsible for emphysema occurs in the tissue and airspaces of the lung. However, studies designed to test the hypothesis that cigarette smoking produces a functional proteolytic imbalance on the lung surface have produced inconsistent results $(5,6)$. This led our laboratory (9) to suggest that lung proteolysis responsible for emphysema may take place in the pockets that form between the endothelial cells and the PMN that are delayed, in the lung microvasculature, by cigarette smoke exposure $(7,8)$.

The physiologic studies presented here show that the pulmonary blood volume, blood flow, and RBC transit time, which are important determinants of PMN retention in the lung, were the same in control and smoke-exposed animals. The experimental design also allowed us to determine if the PMN delayed by cigarette smoke under these circumstances (8) were activated by quantitating changes in adhesion proteins that are associated with PMN activation. CD11/CD18 is a leukocyte integrin that functions as an adhesion molecule on the PMN plasma membrane and is stored in specific and gelatinase-containing cytoplasmic granules $(17,18)$. In response to activators such as the chemotactic tripeptide formylmethionylleucylphenylalanine (FMLP), phorbol esters, and the calcium ionophore A23187, membrane-associated CD11/CD18 increases within minutes on the cell surface, due to the translocation of preformed glycoproteins from the intracellular pool to the PMN cell surface $(10,19,20)$.

In our studies, plasma membrane-associated CD11/CD18 was demonstrated by the immunogold reaction and then quantified using a technique in which documented inter- and intra-observer differences were small enough to allow different lung regions to be compared. Throughout the lung, the number of $\mathrm{G} / \mu \mathrm{m}$ of PMN surface membrane was $6.0 \pm 2.1$ (mean of control, Table 3). Following cigarette smoke ex- 

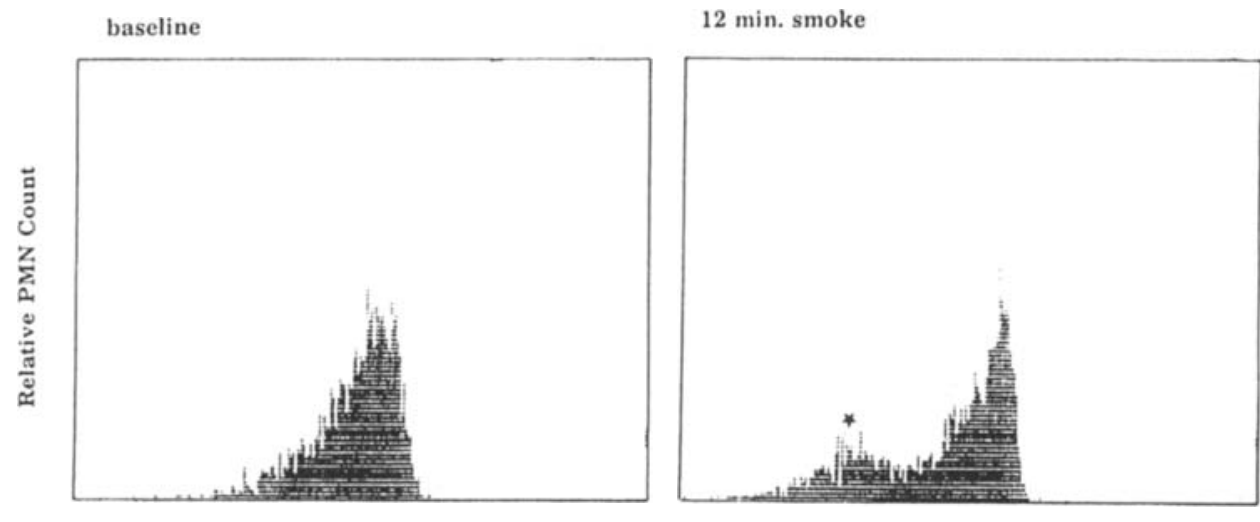

Figure 3. L-selectin expression (shown by FACS analysis of circulating blood) before and after 12 min of smoke exposure. The distribution curve of one of two experiments shows a population of PMN with low L-selectin expression after smoking $(\star)$.

Mean Fluoreseence Intensity

posure, this value increased to $13.2 \pm 3.3 \mathrm{G} / \mu \mathrm{m}$ in the PMN of the upper region of the lung (Table 4). These data combined with the frequency distribution of CD11/CD18 expression shown in Table 5 indicate that most PMN in the upper region of the lung increased their expression of $\mathrm{CD} 11 / \mathrm{CD} 18$ by 50 to $100 \%$. This regional difference in the increase of CD11/CD18 could be partially attributed to the nonuniform smoke distribution in the lung because smoke-related particles are preferentially distributed towards the upper lobes (21). Alternatively, the observed increase in CD11/CD18 expression could be due to a slow clearance of the toxic products of cigarette smoke from the upper region because the ventilation to perfusion ratio is higher in this area (22). In addition, the longer PMN transit times in this region of the lung (8) could allow more time for the PMN to become activated and increase $\mathrm{CD} 11 / \mathrm{CD} 18$ expression.

Our studies also show that cigarette smoke exposure reduced the expression of L-selectin on the surface of PMN in both regions of the lung (Table 6); however, this reduction was more pronounced in the upper than the lower region. Decreased expression of L-selectin in both regions of the lung suggests that changes in the expression of this receptor may occur early in the cascade of events that occur when PMN become activated from cigarette smoke exposure. Although a decrease of surface receptors often occurs through loss of an epitope on the surface protein or through receptor internalization and degradation, L-selectin is thought to be downregulated by release of the molecule from the cell surface (shedding). Shedding of L-selectin has been previously demonstrated in mouse and human PMN exposed to phorbol esters or chemoattractants (such as C5a or leukotriene $\mathrm{B}_{4}$ ) $(10,11)$. Whether such shedding occurs through a proteolytic cleavage near the plasma membrane $(11,23)$ or through the generation and release of protein-containing exosomes (24) is not yet known.

The failure to show a significant change in the expression of CD11/CD18 or L-selectin in the circulating cells, by flow cytometry analysis, strongly suggests that the activated cells remain in the lung during the course of the experiment. However, the small but distinct population of PMN expressing low levels of L-selectin seen in two of the smoke-exposed rabbits (Figure 3) suggests that a circulating pool of smokeactivated PMN may develop with chronic exposure to cigarette smoke. This observation suggests that L-selectin shed- ding is an early and possibly more sensitive parameter for PMN activation by cigarette smoke.

The cigarette smoking habit has been linked to the presence of centrilobular emphysema in human lungs in a wide variety of pathologic studies (25-27). PMN have been implicated in this lung destruction because of their recognized capability of destroying tissue when activated $(28,29)$. Previous studies from our laboratory $(7,8)$ have shown that PMN are delayed, in the lung microvessels, by cigarette smoke, and the present data provide evidence that these cells are activated. Interestingly, the pocket areas that form between the PMN and the endothelium also contained CD11/CD18 molecules (Figures $1 \mathrm{c}$ to $1 \mathrm{e}$ ). We postulate that the formation of these pockets is a crucial step in creating a proteolytic imbalance because they provide "protected areas" where $\alpha_{1} \mathrm{PI}$ is functionally inactivated by oxidants that are either present in the smoke or generated by the PMN. This functional inactivation of an $\alpha_{1} \mathrm{PI}$ in the immediate vicinity of enzyme release from the PMN could allow active enzyme to bind to collagen and cause damage to the alveolar wall. Since upregulation of $\mathrm{CD} 11 / \mathrm{CD} 18$ requires fusion of specific granules with the plasma membrane, granule contents such as lysozyme and collagenase could be released into these pockets in close apposition to the endothelium. We postulate that the functional proteolytic imbalance responsible for emphysema is created in these pockets and suggest that greater activation of PMN in the upper lung regions is consistent with the observation that the centrilobular emphysematous lesions tend to be more prevalent in the upper regions of the lungs.

Acknowledgments: This work was supported by MRC 4219 and the B.C. Health Care Research Foundation and the Respiratory Health Network of Centres of Excellence. Dr. Doerschuk is the recipient of a Career Investigator Award from the American Lung Association.

\section{References}

1. Gross, P., M. A. Babyak, E. Tolker, and M. Kasehak. 1964. Enzymatically produced pulmonary emphysema: a preliminary report. J. Occup. Med. 6:481-484.

2. Laurell, C. B., and S. Eriksson. 1963. The electrophoretic alpha 1-globulin pattern of serum in alpha 1-antitrypsin deficiency. Scand.J. Clin. Lab. Invest. 15:132-140.

3. Janoff, A. 1983. Biochemical links between cigarette smoking and pulmonary emphysema. I. Appl. Physiol. 55:285-293.

4. Janoff, A. 1985. Elastases and emphysema. Current assessment of the protease-antiprotease hypothesis. Am. Rev. Respir. Dis. 132:417-433.

5. Gadek, J. E., G. A. Crystal, and R. G. Crystal. 1979. Cigarette smoking 
induces a functional anti-protease deficiency in the lower respiratory tract of humans. Science 206:1315-1316.

6. Stone, P. J., J. D. Gallore, S. E. McGowan, J. Bernado, G. L. Snyder, and C. Fransblau. 1983. Functional alpha-1 protease inhibitor in the lower respiratory tract of smokers is not decreased. Science 221:11871189

7. MacNee, W., B. Wiggs, A. S. Belzberg, and J. C. Hogg. 1989. The effect of cigarette smoking on neutrophil kinetics in human lungs. N. Engl. J. Med. 321:924-928.

8. Bosken, C. H., C. M. Doerschuk, D. English, and J. C. Hogg. 1991. Neutrophil kinetics during active cigarette smoking in rabbits. J. Appl. Physiol. $71: 630-637$.

9. Brumwell, M. L., W. MacNee, C. M. Doerschuk, B. Wiggs, and J. C Hogg. 1991. Neutrophil kinetics in normal and emphysematous regions of human lungs. Ann. NY Acad. Sci. 624:30-39.

10. Kishimoto, T. K., M. A. Jutila, E. L. Berg, and E. C. Butcher. 1989. Neutrophil Mac-1 and MEL-14 adhesion proteins inversely regulated by chemotactic factors. Science 245:1238-1241.

11. Butcher, E. C. 1990. Cellular and molecular mechanisms that direct leukocyte traffic. Am. J. Pathol. 136:3-11.

12. Hogg, J. C., B. A. Martin, S. Lee, and T. McLean. 1989. Regional differ ences in erythrocyte transit in normal lungs. J. Appl. Physiol. 59: $1266-1271$.

13. Lindbom, L., C. Lundberg, J. Prieto, J. Raud, P. Nortamo, C. G. Gahmberg, and M. Patarroyo. 1990. Rabbit leukocyte adhesion molecules CD11/CD18 and their participation in acute and delayed inflammatory responses and leukocyte distribution in vivo. Clin. Immunol. Immunopathol. 57:105-119.

14. Picker, L. J., R. A. Warnock, A. R. Burns, C. M. Doerschuk, E. L. Berg, and E. C. Butcher. 1991. The neutrophil selectin LECAM-1 presents carbohydrate ligands to the vascular selectins ELAM-1 and GMP-140. Cell 66:921-933.

15. Griffiths, A., A. McDowall, R. Back, and J. Dubochet. 1984. On the preparation of cryosections for immunocytochemistry. J. Ultrastruct. Res. 89:65-78.

16. Montgomery, D. C. 1976. Design and Analysis of Experiments. J. Wiley \& Sons, New York.

17. Jones, D. H., F. C. Schmalstieg, H. K. Hawkins, B. L. Burr, H. E.
Rudloff, S. Krater, C. W. Smith, and D. C. Anderson. 1988. Characterization of a new mobilizable Mac-1 (CD11b/CD18) pool that co-localizes with gelatinase in human neutrophils. In Leukocyte Adhesion Molecules. T. A. Springer, et al., editors. Springer-Verlag, New York.

18. Styrt, B. 1989. Species variation in neutrophil biochemistry and function. J. Leukoc. Biol. 46:63-74.

19. Patarroyo, M., and M. W. Makgoba. 1989. Leucocyte adhesion to cells Molecular basis, physiological relevance, and abnormalities. Scand. $J$. Immunol. 30:129-164.

20. Tonnesen, M. G., D. C. Anderson, T. A. Springer, A. Knedler, N. Avdi, and P. M. Henson. 1989. Adherence of neutrophils to cultured human microvascular endothelial cells. J. Clin. Invest. 83:637-646.

21. Pearson, M. G., S. Vinitski, M. J. Chamberlain, and W. K. C. Morgan. 1984. Regional deposition of particles in the lung during cigarette smoking. Proc. Br. Thor. Soc. 39:716-717. (Abstr.)

22. Cockcroft, D. W., and S. L. Horne. 1982. Localization of emphysema within the lung. An hypothesis based upon ventilation/perfusion relationships. Chest 4:483-487.

23. Levy, P. C., M. J. Utell, H. B. Fleit, N. J. Roberts, Jr., D. H. Ryan, and R. J. Looney. 1991. Characterization of human alveolar macrophage $\mathrm{Fc} \gamma$ receptor III: a transmembrane glycoprotein that is shed under in vitro culture conditions. Am. J. Respir. Cell Mol. Biol. 5:307-314.

24. Tedder, T. F. 1991. Cell-surface receptor shedding: a means of regulating function. Am. J. Respir. Cell Mol. Biol. 5:305-306.

25. Petty, T. L., S. F. Ryan, and R. S. Mitchell. 1967. Cigarette smoking and the lungs. Relation to postmortem evidence of emphysema, chronic bronchitis and black lung pigmentation. Arch. Environ. Health 14:172-177.

26. Ryder, R. C., M. S. Dunnill, and J. A. Anderson. 1971. A quantitative study of bronchial mucous gland volume, emphysema and smoking in a necropsy population. J. Pathol. 104:59-71.

27. Thurlbeck, W. M. 1976. Chronic airflow obstruction in lung disease. In Major Problems in Pathology. Vol. 5. J. L. Bennington, editor. W. B. Saunders, Philadelphia. 235-287.

28. Hogg, J. C. 1987. Neutrophil kinetics and lung injury. Physiol. Rev. 67:1249-1295.

29. Weiss, S. J. 1989. Tissue destruction by neutrophils. N. Engl. J. Med. $320: 365-376$ 